\title{
Erratum: Regulation of inducible nitric oxide synthase activity/expression in rat hearts from ghrelin-treated rats
}

\author{
Emina Sudar • Branislava Dobutovic • Sanja Soskic • Vesna Mandusic • \\ Zorica Zakula • Maja Misirkic • Ljubica Vucicevic • Kristina Janjetovic • \\ Vladimir Trajkovic • Dimitri P. Mikhailidis • Esma R. Isenovic
}

Received: 5 August 2010 /Revised: 9 November 2010 / Accepted: 9 November 2010 /Published online: 14 January 2011

(C) University of Navarra 2011

\section{Erratum to: J Physiol Biochem \\ DOI: $10.1007 / \mathrm{s} 13105-010-0063-1$}

The authors of the above mentioned article wish to thank the institutes and their colleagues who supported this work in the following acknowledgment:

This work was supported by grants No. 143030B (to ERI), No. 145073 (to VT) and No. 145003 (to VS) funded by the Ministry of Science, Republic of Serbia. We would like to thank to Prof. V. Starcevic for her expertise in neuroendocrine ghrelin actions.

The online version of the original article can be found at http:// dx.doi.org/10.1007/s13105-010-0063-1.

E. Sudar $\cdot$ B. Dobutovic $\cdot$ S. Soskic $\cdot$ V. Mandusic $\cdot$

Z. Zakula $\cdot$ E. R. Isenovic $(\bowtie)$

Laboratory of Radiobiology and Molecular Genetics, Institute Vinca, University of Belgrade,

P.O. Box 522, 11001 Belgrade, Serbia

e-mail: isenovic@yahoo.com

M. Misirkic $\cdot$ L. Vucicevic $\cdot$ K. Janjetovic

Institute for Biological Research "Sinisa Stankovic",

University of Belgrade,

Despota Stefana 142, 11000 Belgrade, Serbia
We thank Drs. D. Stevanovic, D. Nesic and M. Djelic for their excellent contribution in in vivo experimental design, and we would like also to stress out that we are grateful to them for their performances of stereotaxically intracerebroventricular implantation of cannulas, ICV ghrelin treatment for 5 days as well as for their great help with animal sacrifices, collecting blood samples, organs' excision and weighing, and help in writing 'Materials and Methods' section related to in vivo part of the experiments.

\footnotetext{
V. Trajkovic

Institute of Microbiology and Immunology,

School of Medicine, University of Belgrade,

Dr. Subotica 1, 11000 Belgrade, Serbia

D. P. Mikhailidis

Department of Clinical Biochemistry (Vascular Disease

Prevention Clinics), Royal Free campus,

University College London Medical School,

University College London (UCL),

Pond Street, London NW3 2QG, UK
} 